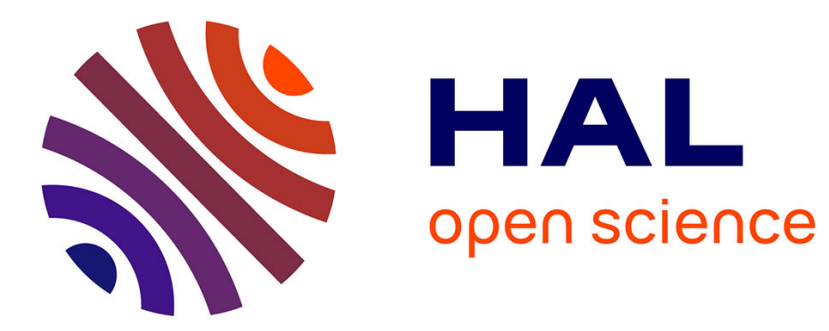

\title{
Reperfusion in acute ischaemic stroke by sonothrombolysis
}

\author{
Maxime Gauberti
}

\section{To cite this version:}

Maxime Gauberti. Reperfusion in acute ischaemic stroke by sonothrombolysis. The Lancet Neurology, 2019, 18, pp.320 - 321. 10.1016/S1474-4422(19)30066-3 . hal-03486425

\section{HAL Id: hal-03486425 \\ https://hal.science/hal-03486425}

Submitted on 21 Dec 2021

HAL is a multi-disciplinary open access archive for the deposit and dissemination of scientific research documents, whether they are published or not. The documents may come from teaching and research institutions in France or abroad, or from public or private research centers.
L'archive ouverte pluridisciplinaire HAL, est destinée au dépôt et à la diffusion de documents scientifiques de niveau recherche, publiés ou non, émanant des établissements d'enseignement et de recherche français ou étrangers, des laboratoires publics ou privés.

\section{다)(1) $(5$}

Distributed under a Creative Commons Attribution - NonCommerciall 4.0 International 


\section{Promoting reperfusion in acute ischemic stroke by sonothrombolysis}

Comment on "Efficacy and safety of sonothrombolysis for acute ischemic stroke: a multicentre, double-blind, phase 3, randomised controlled trial".

Maxime GAUBERTI ${ }^{1,2}, \mathrm{PhD}$

1. Normandie Univ, UNICAEN, INSERM, INSERM UMR-S U1237, "Physiopathology and Imaging of Neurological Disorders" PhIND, 14000 Caen, France.

2. CHU Caen, Department of Diagnostic Imaging and Interventional Radiology, CHU Caen Côte de Nacre, 14000 Caen, France.

This manuscript includes 665 words in the main text and 6 references.

Maxime Gauberti, PhD, INSERM U1237 "Physiopathology and Imaging for Neurological

Disorders (PhIND)", GIP Cyceron, Bd Henri Becquerel, 14074 Caen, France, Phone:

0033.231.47.01.55, Fax: 33.231.47.02.22, gauberti@cyceron.fr 


\section{TEXT}

The treatment of acute ischemic stroke has rapidly evolved in the last few years. The development of mechanical thrombectomy has allowed to reach high rates of reperfusion in patients with proximal occlusion, while the efficacy of intravenous thrombolysis was limited in this subset of patients ${ }^{1}$. Yet, the situation is far from ideal: endovascular reperfusion therapies are not available in most stroke centers across the world, delays between imaging and actual reperfusion by means of endovascular procedures are extensive and technical failures are frequent. In this context, there is still a need for more effective medical reperfusion therapies that can be rapidly and widely used in stroke patients.

In their Article in The Lancet Neurology, Andrei Alexandrov and the CLOTBUST-ER Trial Investigators (Combined lysis of thrombus with ultrasound and systemic tissue plasminogen activator for emergent revascularization in acute ischemic stroke) report the results of a double-blind, multicenter, phase III randomized-controlled clinical trial of sonothrombolysis in acute ischemic stroke patients with National Institutes of Health Stroke Scale (NIHSS) scores $\geq 10$ who were eligible for intravenous thrombolysis. After receiving standard of care treatment, including full dose intravenous alteplase, participants were randomly assigned to 2 hours of 2-MHz pulsed-wave ultrasound or sham treatment using an operator-independent device. The use of sonothrombolysis assumes that ultrasound exposure enhances alteplase penetration inside the occluding thrombus, thereby enhancing thrombolysis efficacy, fastening reperfusion and improving stroke outcome. The primary outcome was the adjusted improvement in three-month modified Rankin Scale (mRS).

The results are negative. The trial was stopped early after the second interim analysis due to futility at a time where 335 patients were randomized to the sonothrombolysis group and 341 patients to the control group. The adjusted odd ratio (OR) for 1-point improvement in $\mathrm{mRS}$ -

score in the intervention group was 1.05 (95\% CI: 0.77-1.45). Although there was no strong 
evidence to indicate a difference between groups in safety analyses, there was a trend for a higher rate of cerebral edema, brain herniation and asymptomatic intracranial hemorrhage in the sonothrombolysis group (despite the use of $2 \mathrm{MHz}$ ultrasounds, that are considered safer albeit probably less efficient than lower frequency ultrasounds ${ }^{2}$ ).

Is this negative study the end of sonothrombolysis for acute ischemic stroke? Probably not. Several factors might have influenced the outcome of the CLOTBUST-ER Trial. First, documentation of proximal intracranial occlusion (the target of sonothrombolysis) was not required in this trial, in order to facilitate patient recruitment in stroke centers without access to emergent angiography. Instead, the investigators used severe stroke (NIHSS >10) as a surrogate for large vessel occlusion. Consequently, some of the patients did not have a proximal occlusion within the target area of the ultrasound device. Second, the operator independent ultrasound might have provided less efficient ultrasound exposure as a result of its multi-transduced headframe design. This could explain that the present study did not reproduce the positive findings of previous phase II clinical trials that used "diagnostic", operator dependent, transcranial doppler devices ${ }^{3,4}$. Moreover, several studies suggest that the efficacy of sonothrombolysis can be further enhanced using optimized devices and contrast agents ${ }^{5}$.

Future trials on sonothrombolysis will have to consider the new landscape of acute ischemic stroke diagnosis and treatment. Patient selection should rely on emergent imaging to identify individuals with large vessel occlusion. Moreover, the largest benefit of ultrasound-induced reperfusion is expected in patients that require transfer from a primary to a thrombectomycapable comprehensive stroke center (drip-and-ship paradigm) where the delays between imaging and actual reperfusion are currently the largest. Accordingly, a new sonothrombolysis trial (TRUST, NCT 03519737) has been initiated in which patients with large vessel occlusions in a drip-and-ship paradigm will be randomized to ultrasound or no 
ultrasound using an optimized device with the primary end-point being recanalization prior to thrombectomy. As supported by the results of a recent trial on tenecteplase versus alteplase in a similar design ${ }^{6}$, achieving higher incidence of reperfusion before thrombectomy can translate in better functional outcome. In addition to new thrombolytic, antiplatelet or anticoagulant agents, sonothrombolysis remains a promising tool to achieve this goal. 


\section{REFERENCES}

1. Bhatia R, Hill MD, Shobha $N$, et al. Low rates of acute recanalization with intravenous recombinant tissue plasminogen activator in ischemic stroke: real-world experience and a call for action. Stroke 2010; 41(10): 2254-8.

2. Wilhelm-Schwenkmezger T, Pittermann P, Zajonz K, Kempski O, Dieterich M, Nedelmann M. Therapeutic application of $20-\mathrm{kHz}$ transcranial ultrasound in an embolic middle cerebral artery occlusion model in rats: safety concerns. Stroke 2007; 38(3): 1031-5.

3. Alexandrov AV, Molina CA, Grotta JC, et al. Ultrasound-enhanced systemic thrombolysis for acute ischemic stroke. N Eng/ J Med 2004; 351(21): 2170-8.

4. Chen $Z$, Xue $T$, Huang $H$, et al. Efficacy and safety of sonothombolysis versus nonsonothombolysis in patients with acute ischemic stroke: A meta-analysis of randomized controlled trials. 2019; 14(1): e0210516.

5. Bader KB, Bouchoux G, Holland CK. Sonothrombolysis. Adv Exp Med Biol 2016; 880: 339-62.

6. Campbell BCV, Mitchell PJ, Churilov L, et al. Tenecteplase versus Alteplase before Thrombectomy for Ischemic Stroke. N Engl J Med 2018; 378(17): 1573-82. 